\title{
Legionnaires' disease in Italy: results of the epidemiological surveillance from 2000 to 2011
}

M C Rota (rota@iss.it) ${ }^{1}$, M G Caporali ${ }^{1}$, A Bella $^{1}$, M L Ricci $^{2}$, C Napoli ${ }^{1,3}$

1. Istituto Superiore di Sanità (ISS, National Institute of Health), National Centre for Epidemiology, Surveillance and Health Promotion, Rome, Italy

2. Istituto Superiore di Sanità (ISS, National Institute of Health), Department of Infectious, Parasitic and Immune-Mediated Diseases, Rome, Italy

3. University of Bari, Department of Biomedical Sciences and Human Oncology, Bari, Italy

Citation style for this article:

Rota MC, Caporali MG, Bella A, Ricci ML, Napoli C. Legionnaires' disease in Italy: results of the epidemiological surveillance from 2000 to 2011. Euro Surveill. 2013;18(23):pii=20497. Available online: http://www.eurosurveillance.org/ViewArticle.aspx?Articleld=20497

Article submitted on 03 July 2012 / published on 06 June 2013

According to the Italian Surveillance System for Legionnaires' disease (LD), physicians must fill in a form for every case and send it through the Local Health Units to the National Institute of Health (Istituto Superiore di Sanità, ISS). Forms reported in the period from 2000 to 2011 were analysed and discussed. A total of 9,803 cases of LD were reported to ISS during the study period. The median age of cases was 63 years, with a ratio male/female of 2.6 and a case fatality rate of $11.8 \%$. The number of cases has been steadily increasing from 192 cases in 2000 to 1,235 in 2010 and 1,008 cases in 2011. The reported cases showed a geographical gradient, with the highest number notified in the north and the lowest in the south. The majority of cases $(73.0 \%)$ were communityacquired, followed by travel-associated (13.5\%) and healthcare-associated cases (9.3\%), cases acquired in long-term care facilities (2.1\%), and other types of exposure (2.1\%). Even though the increasing trend of LD in Italy indicates an improvement in the ability to detect and report cases, the geographical gradient highlights the existence of low reporting areas where the epidemiological surveillance of LD should be further strengthened.

\section{Introduction}

Legionella spp. is a ubiquitous intracellular microorganism colonising natural and artificial aquatic environments, which grows at temperatures of 25 to $42^{\circ} \mathrm{C}$ [1-2]. Presently, a total of 55 species and more than 70 serogroups has been classified [3]; Legionella pneumophila serogroup 1 (Lp1) is the most frequently reported aetiological agent in community-acquired legionellosis, although also other serogroups, especially Lp4 and Lp6, are frequently involved in hospitalacquired cases and outbreaks, as well as other species commonly indicated as Legionella species (L. anisa, L. bozemanii, L. dumoffii, L. longbeachae, L. micdadei) [4-9].

Legionnaires' disease (LD) is a form of interstitial pneumonia that is normally transmitted via aerosol, i.e. inhalation of mist droplets containing the bacteria. The aerosol containing Legionella bacteria can be produced by contaminated water sources such as cooling towers, domestic hot-water systems, swimming and spa pools, fountains, respiratory therapy equipment, and other devices that tap into a public water supply. No inter-human transmission has been documented, therefore it can be presumed that natural and artificial aquatic environment is the only source of the infection. Individual risk factors such as long-term medical conditions, heavy smoking or alcohol abuse, and environmental risk factors may influence the likelihood to develop the infection. The problem is particularly relevant in contaminated healthcare facilities because the onset of the disease and its outcome are influenced by the patient's pre-existing pathologies and level of immunocompetence $[9,10]$. In addition, medical equipment, if not adequately treated, can also be a potential source of infection in hospitals (endoscopes, food or nasogastric tubes, devices for artificial respiration and oxygen therapy, dental tools, etc.) [10].

Recently, the need to strengthen epidemiological surveillance programmes, to improve diagnostic techniques and to set up preventive measures, e.g. the search for sources of infection, periodical controls of drinking water supply systems, and installation of effective disinfection systems, have become a priority [9-15].

The European Working Group for Legionella Infections (EWGLI) was established in 1986 with the objective of carrying out international surveillance of travelassociated LD. EWGLI was coordinated by the Health Protection Agency in London from 1993 to the end of March 2010, when the European Centre for Disease Prevention and Control (ECDC) took over the management. Since then, it has been named European Legionnaires' Disease Surveillance Network (ELDSNet) and it involves all 27 European Union (EU) Member States, Iceland and Norway [16]. 
In Italy, epidemiological surveillance for LD started in 1983, when the Legionellosis National Registry was established and managed by the Italian National Institute of Health (Istituto Superiore di Sanità, ISS); notification of LD became mandatory in 1990. Since then, the number of sporadic and epidemic cases has been growing constantly, but the increase seems due to better reporting and/or improved diagnosis rather than to an increased incidence of the disease $[9,17,18]$.

The objective of this paper is to present the results of the Italian surveillance programme during the period from 2000 to 2011.

\section{Methods}

\section{Surveillance system}

According to the National Surveillance of LD, for each case of LD diagnosed in Italy, physicians must fill in a surveillance form and send it to the Local Health Units (LHU). The LHU has to start investigations of the epidemic and the environment. The LHU staff interview cases and their relatives to assess risks of contracting LD, to find out about sources of exposure and other LD cases potentially connected to a common source. Potential sources of contamination are investigated and, jointly with the Local Agency for the Environment, water samples are collected for laboratory analysis. The completed notification form is then sent to the ISS, which monitors trends, studies the epidemiological characteristics of LD patients, and looks for clustered cases not identifiable at the local level.

The form reports the patients' socio-demographic data (age, sex, place of residence), clinical data (date of symptom onset, date of hospitalisation, patient outcome), risk factors, patient lifestyle before disease onset (exposure to any of the following settings during the 10 day-incubation period preceding symptom onset: hospitals, dental outpatient clinics, prisons and barracks, hotels, campsites and other recreational facilities such as spas, swimming pools, etc.), laboratory diagnostic tests, and whether an environmental investigation has been carried out.

The forms sent to ISS are classified according to the case definition as confirmed or probable LD, and as community-, hospital- or travel-associated LD, and are entered in a specific database and analysed. Moreover, all cases of travel-associated LD that occurred in foreign travellers who had visited Italy in the 10 days before onset of the disease, and that are reported to ISS by ECDC in the same period, are entered in the database and analysed [16].

The role of the National Reference Laboratory for Legionella in the epidemiological surveillance is to confirm LD diagnosis, when the regional reference laboratories lack sufficient capacity to perform the required assays and to carry out molecular typing and matching of clinical and environmental strains.

\section{Case definition}

According to the national Guidelines for Legionella spp. Control and Prevention [14], a confirmed case of LD is a patient presenting clinical and/or radiological signs of pneumonia associated with at least one of the following laboratory criteria: (i) isolation of Legionella spp. from a culture of bronco-pulmonary secretions, (ii) a four-fold increase in IgG antibody titres for L. pneumophila 1, and (iii) a positive urinary antigen test.

A probable case is a patient presenting clinical and/or radiological signs of pneumonia associated with a single high level of specific antibodies to L. pneumophila 1 ( $\geq 1: 256)$, or a positive direct immunofluorescence test, or a positive PCR.

In healthcare settings (hospitals and care homes for the elderly), a definite healthcare-associated case is an LD case that occurred in a patient continuously hospitalised during the 10-day period before symptom onset. If hospitalisation has not been continuous, the case is considered as a possible healthcare-associated case. A healthcare-associated cluster is defined by two or more probable or confirmed cases who stayed in the same hospital in the period two to 10 days before the symptom onset and whose symptom onset was within the same six-month period [14].

Travel-associated single cases are defined as cases who, in the ten days before onset of the illness, stayed at or visited an accommodation site never before associated with cases of LD, or cases who stayed at an accommodation site linked to other cases of LD that occurred more than two years previously [13]. A travelassociated cluster is defined by two or more cases who stayed at or visited the same accommodation site in the period two to 10 days before symptom onset and whose symptom onset was within the same two-year period [13].

The term re-offenders, according to the EWGLI definition [19], applies to those accommodation sites (hotels, campsites, apartments, etc.) that are found to be associated with at least one further case within the same two-year period after a cluster had been detected and investigated.

An outbreak is defined as the occurrence of a minimum of 10 cases of LD who are associated in time and place and share a common exposure to a contaminated source.

\section{Data analysis}

Results are expressed as median and interquartile range (IQR) or as frequencies and percentage. Differences among percentages were assessed by the chi-square test or, when appropriate, by chi-square test for trend. Data were also analysed by sex and geographical area. Northern Italy included the regions of Piedmont, Lombardy, the Autonomous Province of Trento, the Autonomous Province of Bolzano, Veneto, 
Friuli Venezia Giulia, Liguria, and Emilia-Romagna; central Italy included Tuscany, Umbria, Marches, and Lazio; southern Italy included Abruzzo, Molise, Apulia, Calabria, Sicily, and Sardinia.

The annual incidence of LD per million population was calculated using the Italian population data provided for the corresponding year by the National Institute of Statistics (ISTAT) [20]. All statistical analyses were performed using STATA software version 11.2 (STATA Corporation, College Station, Texas, United States).

\section{Results}

\section{Case characteristics}

During the study period, a total of 9,803 cases of LD were reported to ISS (annual mean: 817; range: 192$1,235)$. The median age of cases was 63 years (IQR: 24 years), 7,068 (72.1\%) were male and 2,735 (27.9\%) female, a male/female ratio of 2.6. Figure 1 shows the incidence rates per 1 million population of LD cases by sex and age group. Overall, 9,295 (94.8\%) cases were confirmed. The number of cases has been increasing steadily during the study years: 192 cases were notified in 2000, a three-fold increase was identified in 2002, and a further two-fold increase was registered in 2008, reaching a peak of 1,235 cases in 2010. In 2011 a small decrease was registered with 1,008 notified cases (Table).

A statistically significant upward trend was observed in the 12-year surveillance period ( $p<0.0001)$. When analysing the data by geographical area (northern, central and southern Italy), a similar upward trend was observed for each area (p<0.0001) (Figure 2). Indeed,

\section{FIGURE 1}

Incidence rates per 1 million inhabitants of Legionnaires' disease cases by sex and age, Italy, 2000-2011 ( $\mathrm{n}=9,803)$

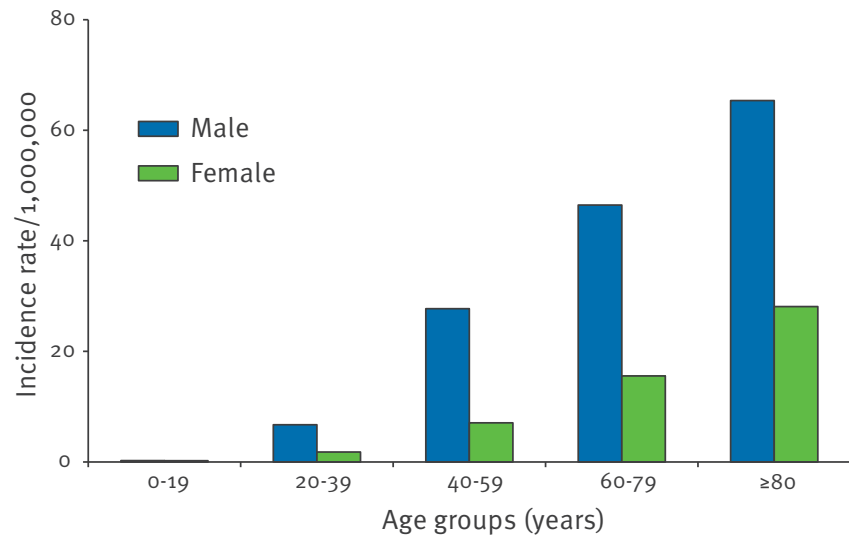

the overall annual incidence increased from 3.4 per million inhabitants in 2000 to 16.6 per million inhabitants in 2011 (Figure 2), with a mean annual growth rate of $20.1 \%$ (range: $18.3-92.4 \%$ ).

However, the reported cases showed a consistent and significant geographical gradient, with the highest number notified in the north and the lowest in the south, which did not change during the study period. In the northern regions, incidence increased from six cases per million inhabitants in 2000 to 25.1 cases per million inhabitants in 2011 , in the central regions from

TABLE

Legionnaires' disease cases diagnosed by year and exposure, Italy, 2000-2011 (n=9,803)

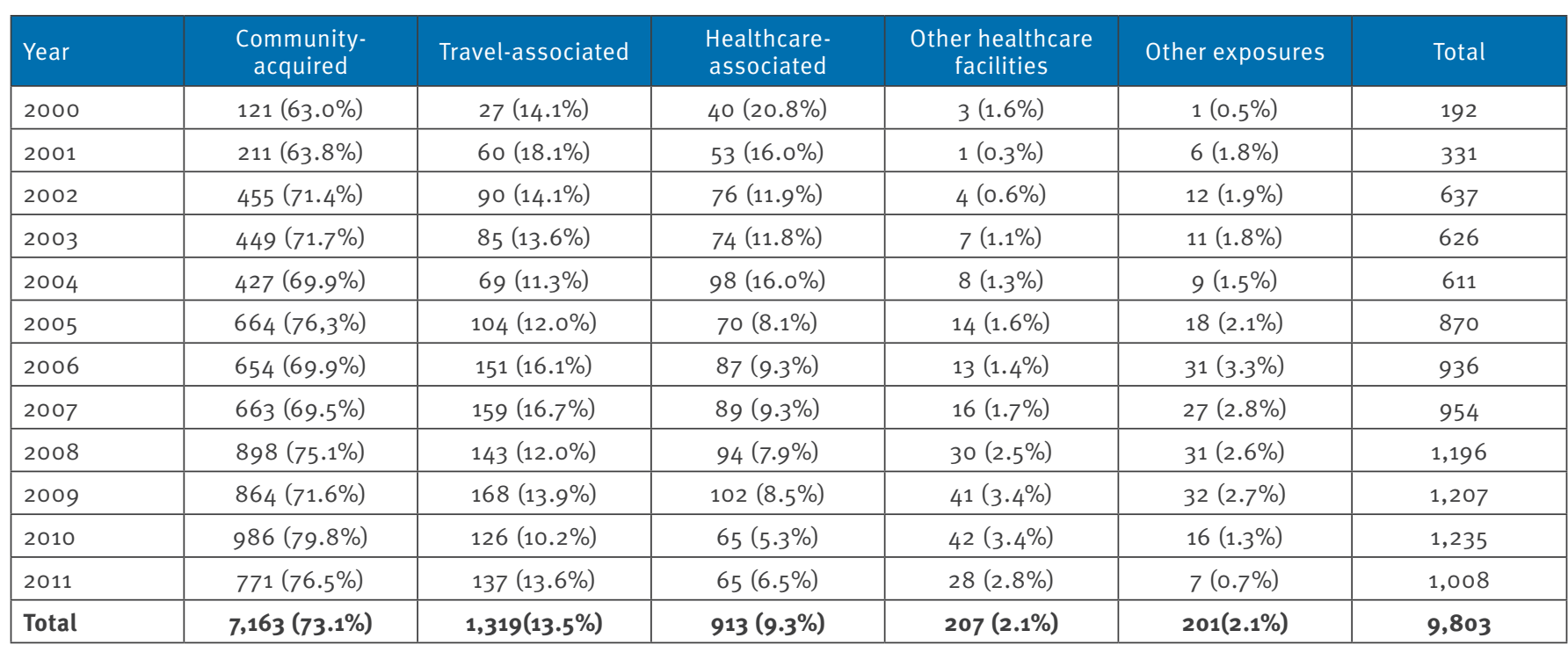


Legionnaires' disease incidence by year of onset and geographical area, Italy, 2000-2011 (n=9,803)

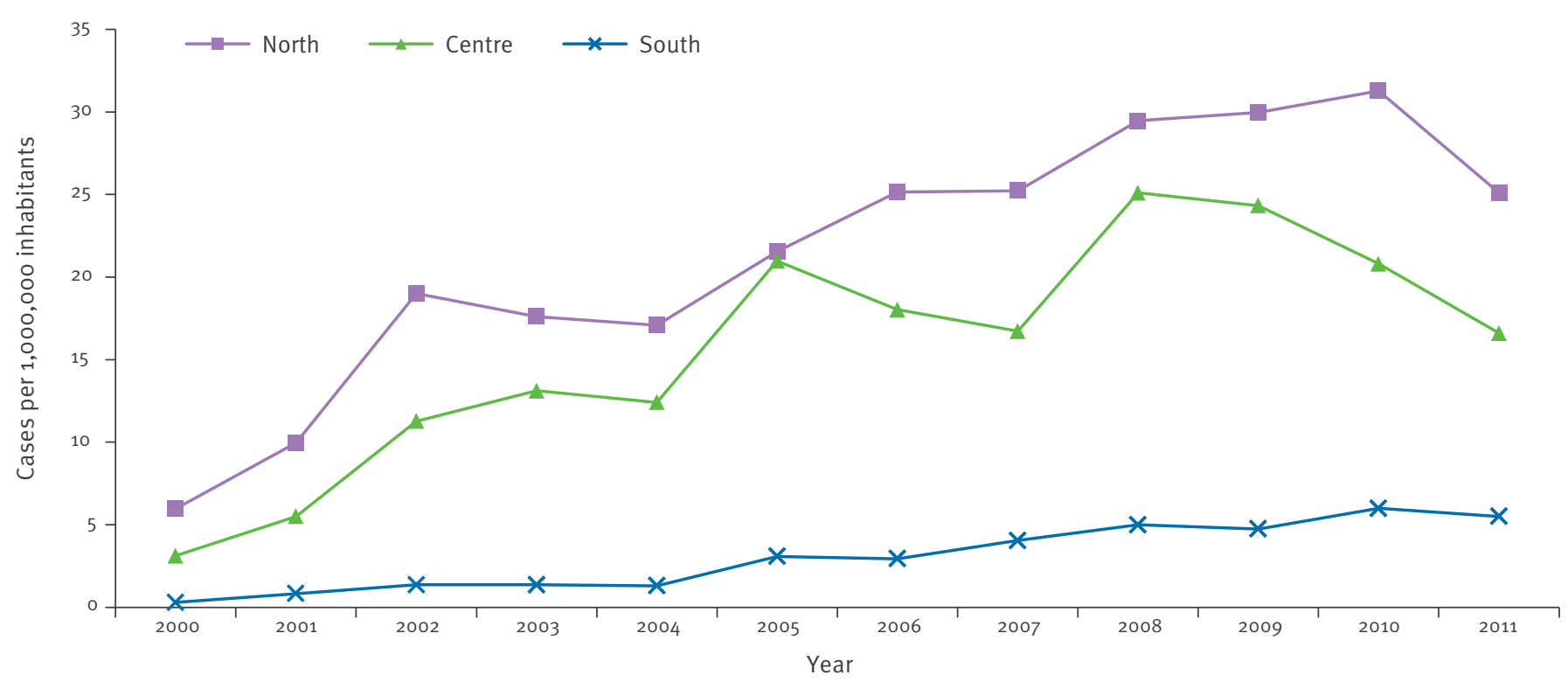

3.1 to 16.6 per million inhabitants, and in the southern regions from 0.3 to 5.5 per million inhabitants. Figure 3 shows the incidence rate by region in 2000 and 2011. When comparing the annual incidences in the three geographical areas, a statistically significant difference was observed for the entire study period, except for the year 2005 when the incidences in northern and central areas did not differ statistically $(p=0.739)$ because two regions belonging to the central area reported a higher number of cases than usual (the reason is unknown since no outbreak were detected) (Figure 2).

Among the 9,803 notified cases, 5,326 (54.3\%) reported at least one underlying disease. Chronic diseases, including respiratory or cardiac diseases and diabetes, were reported in $3,735(70.1 \%)$ of these, cancer in 766 (14.4\%), infectious diseases in 304 (5.7\%), organ transplantation in 114 (2.1\%), immunosuppressive condition in $74(1.4 \%)$ cases, and other diseases in 333 cases $(6.3 \%)$.

Stratifying cases by age, 3,278 out of 9,803 (33.4\%) were older than 70 years. In this age group the proportion of individuals with underlying disease was $73.3 \%$, significantly higher than among younger individuals (48.6\%; p<0.0001).

The main risk factor was tobacco smoke, which was reported in 4,163 of 9,803 patients $(42.5 \%)$.

\section{Cases by setting}

When analysing the cases by setting, the majority $(7,163,73.0 \%)$ were community-acquired cases, followed by 1,319 (13.5\%) travel-associated cases, $913(9.3 \%)$ healthcare-associated cases of whom 881 were confirmed and 32 were probable, and 207 (2.1\%) cases acquired in long-term care facilities. Some 201 (2.1\%) cases reported other types of exposure such as swimming pools, dental outpatient clinics and prison (Table).

The annual number of healthcare-associated cases increased during the surveillance period from 40 cases in 2000 to a maximum of 102 cases in 2009. However, due to a more evident increase in the percentage of community-acquired cases, the proportion of healthcare-associated cases diagnosed decreased significantly. In fact, the percentage of community-acquired cases increased from $63 \%$ in the year 2000 to a maximum of $79.8 \%$ in 2010 , while healthcare-associated cases decreased from $20.8 \%$ to $5.3 \%$.

During the study period, the 913 reported healthcareassociated cases involved 228 hospitals. The mean number of cases per hospital was 4.0 (range: 1-82), whereby 116 hospitals were associated with only one case, 42 reported only sporadic cases (more than one case with no epidemiological link), and 70 reported at least one cluster. Of the latter, 29 hospitals were associated with repeated clusters up to a maximum of eight, and overall, the 70 hospitals reported 666 healthcareassociated cases.

Also the number of travel-associated LD cases that occurred in Italian tourists hospitalised in Italy rose during the study period, with some fluctuation from 27 cases in 2000 to a maximum of 168 cases in 2009 


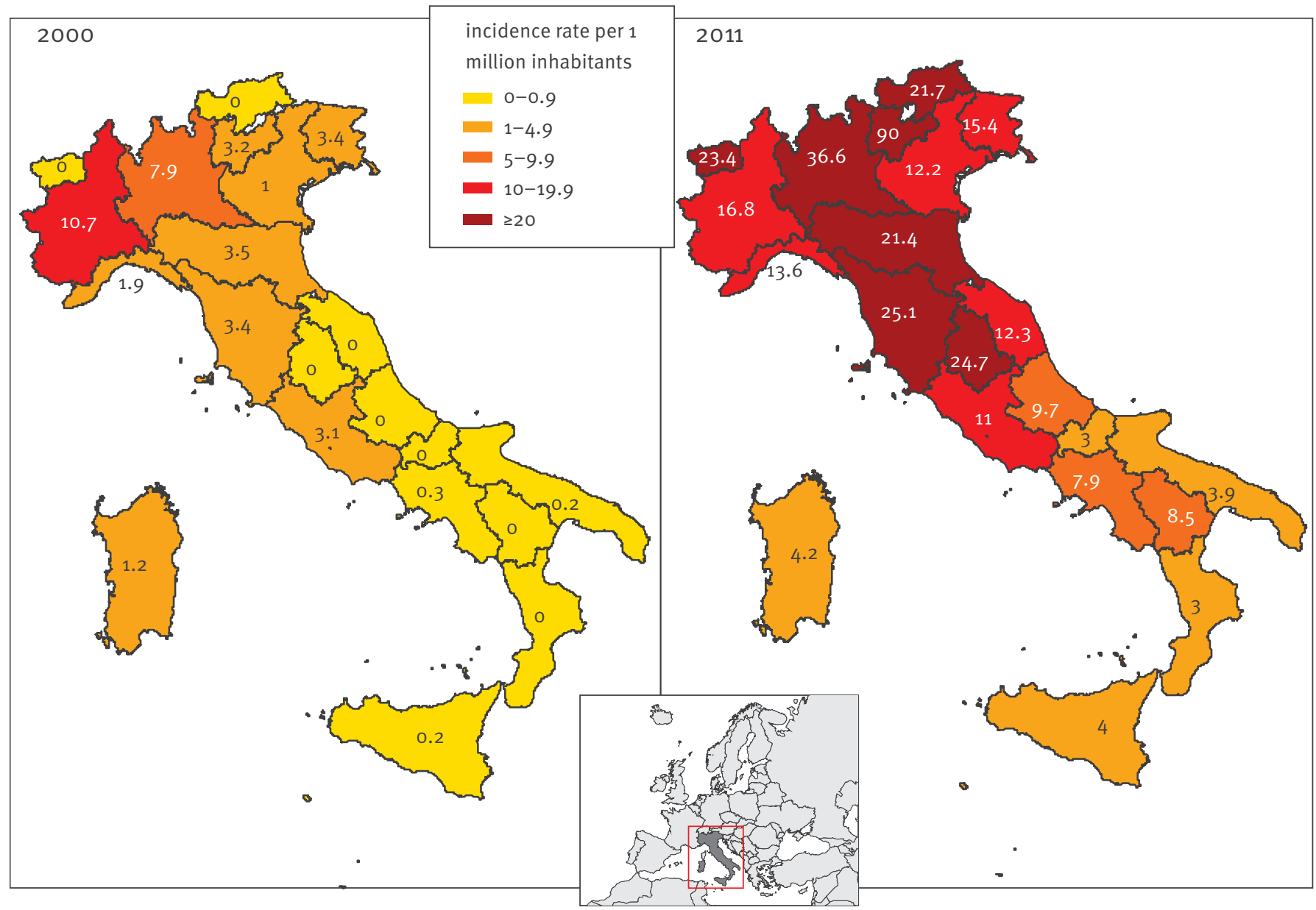

(Table and Figure 4). Moreover, EWGLI/ELDSNET reported to ISS that 904 travel-associated LD cases occurred in foreign tourists travelling to Italy; also the number of these cases increased steadily during the study period, reaching a peak in 2007 (Figure 4).

The category Other exposures showed a peak in 2006 of $3.3 \%$ of the total cases. It should be noted that among these, the most frequently reported exposures during the entire study period were dental outpatient clinics (39.3\%) and swimming pools (41.8\%).

From 2002, when the European Guidelines for Control and Prevention of Travel Associated Legionnaires' disease were enforced in Europe and consequently also in Italy, to 2011, 320 Italian accommodation sites were associated with clusters of LD, 79 of which were reoffenders. The number of clusters increased gradually from 2002, and peaked in 2007, when 71 clusters were notified (of which 20 occurred in re-offending sites). From 2008, the number of clusters started to decrease, and in 2011, 46 accommodation sites were reported (of which 14 were re-offenders). The largest cluster of
TALD occurred in 2011 in a touristic area in northern Italy, involving 17 tourists from five European countries who had stayed in five accommodation sites [21].

According to EWGLI Guidelines [13], all these accommodation sites underwent a risk assessment and environmental controls, and 191 of the 320 sites tested positive for Legionella spp. Investigation results were reported within six weeks to EWGLI/ELDSNET.

\section{Diagnostic methods and disease outcome}

Overall, $92.5 \%$ of cases were diagnosed by urinary antigen test, which was the most used diagnostic method. Culture was performed in $2.3 \%$ of cases, while a four-fold increase in antibody, a single antibody titre, PCR and direct immunofluorescence were used in, respectively, 3.0, 7.4, 0.4 and $0.1 \%$ of cases (some cases may have been diagnosed with more than one method). Some $94.3 \%$ of cases were diagnosed by only one laboratory method, two methods were used in $5.4 \%$, and three in $0.2 \%$ of cases. The use of diagnostic techniques evolved over time with an increasing proportion of urinary antigen testing (50.5\% in 2000 versus $94.0 \%$ in 2011 ; p $<0.0001$ ) used as the only one 


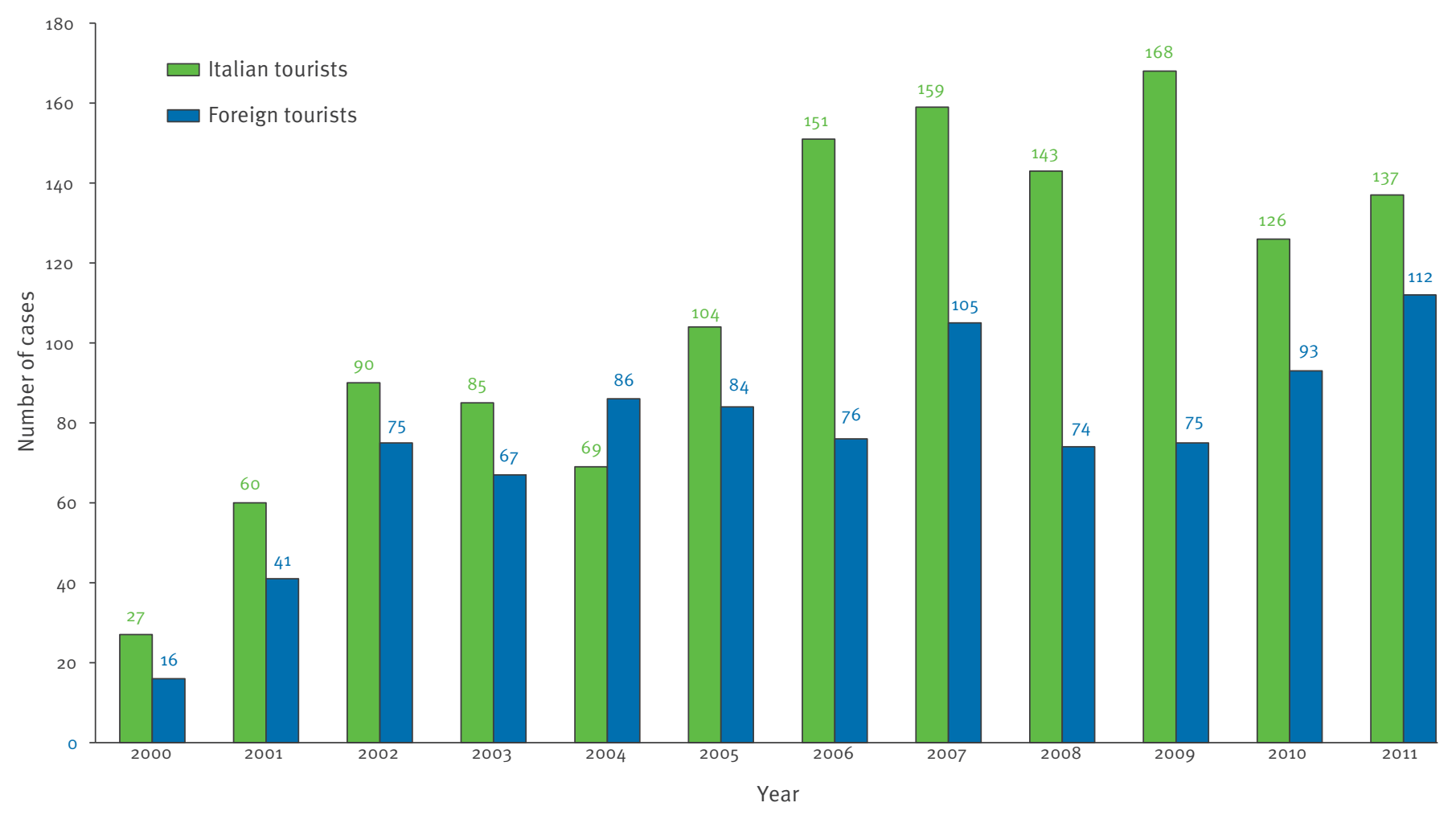

diagnostic method. By contrast, the use of culture as a unique method has decreased from $3.6 \%$ in 2000 to $1.9 \%$ in $2011(p=0.001)$.

The outcome of the disease in the study period was reported for $50.7 \%$ of the cases, with a case fatality rate of $11.8 \%$ (annual range: $8-17 \%$ ) and with no differences by sex ( $p>0.05)$.

\section{Community outbreaks}

During the study period, three major community outbreaks occurred and were thoroughly investigated. In the two months from 15 August to 18 October 2003, 15 cases of LD were reported in the city of Rome. In order to identify sources of exposure to Legionella, environmental investigations were made along with a matched case-control study. This brought to light that people who were regular customers at a certain department store in the area had an almost 10 -fold greater risk of contracting the disease (odds ratio: 9.8 ; $95 \%$ confidence interval: 2.1-46.0). An Lp1 was found in the store's cooling tower. The cause of the epidemic was a single strain of Lp1, and this finding was supported by phenotypic and genotypic analysis conducted on human and environmental isolates; the cooling tower was shown to be the origin of the infection [22].

From 20 July to 31 August 2006, an outbreak of 15 confirmed LD cases was detected in Venice. Extensive epidemiological and environmental investigations were conducted to identify the possible source of the outbreak; however, the lack of clinical specimens to match with environmental isolates prevented identification of the source of infection. Nevertheless, disinfection of the cooling towers identified as positive for Legionella spp. in the city centre was performed and no more cases were observed.

From 21 December 2005, the number of LD cases notified by the city of Cesano Maderno (a town with 30,000 inhabitants in the north of Italy) started to increase, and by 2 March 2008, 40 confirmed LD cases had been notified, with an annual local incidence ranging from 400 to 700 cases per 1 million population. Epidemiological and environmental investigations started in early 2006 and, in spite of the huge number of air and water samples collected from the patients' homes, industrial and public building cooling tower, as well as the municipal water system, clear evidence of the source of infection was never obtained, even though $49 \%$ of the patients' homes tested positive for LP1 and the only two clinical strains available had the same genomic profile (ST23) as those cultured from 11 houses, suggesting that the household water systems were a possible source of infection. In spite of extensive prevention measures adopted nowadays, cases are still being reported, and the incidence rate in Cesano Maderno continues to be much higher than anywhere else in Italy. 


\section{Discussion}

The 12-year epidemiological surveillance data show that in Italy there has been a substantial increase of reported LD cases. This increase reflects the increased incidence registered all over Europe [23]. Moreover, while in 2000 and 2001, the incidence rate in Italy was lower than the European average (3.4 and 5.8 per million inhabitants versus 5.4 and 7.6 per million inhabitants, respectively, for 2000 and 2001), since 2002 it has been higher than the European rate, with a peak in 2010 (20.5 per million inhabitants versus 12.4 per million inhabitants) [17]. In 2010, only the Netherlands, Spain, France, Slovenia, and Denmark showed higher incidence rates than Italy; nevertheless, the differences between countries must be discussed with caution, because there are many factors that influence notification rates, such as the practitioners' awareness, the compliance of clinicians with the surveillance system, and the effect of local regulations or guidelines on prevention measures [24]. In spite of the increasing reporting trend, the reported incidence rate in Europe is still lower than the true rate, which is estimated to be 100 cases per million inhabitants [25], and several countries, in particular in south-eastern Europe, are still reporting less than one case per million.

Our study highlights that in Italy, the proportion of cases associated with different exposures has changed over time. The percentage of community-acquired cases increased from $63.0 \%$ in 2000 to $76.5 \%$ in 2011 , while healthcare-associated and travel-associated cases decreased from $20.8 \%$ to $6.4 \%$ and from $14.0 \%$ to $13.5 \%$, respectively, in the same years. The reduction in travel-associated LD cases may be the result of an improvement in control and prevention measures implemented in hotels and other accommodation sites in accordance with the enhanced surveillance implemented in the European Member States that participate in EWGLINET in the past and to ELDSnet since 2010.

In the past few years, greater attention has also been paid to the prevention and control of legionellosis in healthcare facilities in Italy, although the problem of healthcare-associated legionellosis remains relevant, highlighting the difficulty in eradicating the microorganism from the water systems, despite regular maintenance and monitoring [9].

The observed increase in the number of cases of community-acquired LD in Italy is the positive outcome of enhanced surveillance and improved diagnostic capacity developed in the past decade. However, despite the impressive increase in case detection, the incidence is still being underestimated especially in the southern regions of the country as highlighted by the findings of a capture/recapture study conducted in 2002 [26] and a study on LD diagnostic capacity conducted in 2006 [27], which underlined that the level of clinical awareness regarding legionellosis is still low and the reporting, although compulsory, is still missed too often. Although the importance of screening for legionellosis of all pneumonia cases reporting risk factors for the disease is underlined every year in the annual report on legionellosis in Italy, and several training courses for health professionals have been organised both at central and local level, many physicians, especially in southern Italy, still may feel that it is not necessary to confirm the aetiological diagnosis of pneumonia as LD in order to treat it. However, from a public health perspective it is important to confirm the diagnosis and report individual cases, so that they can be fully investigated and possible clusters or outbreaks, whether community-, healthcare- or travel-associated, can be identified. The study on LD diagnostic capacity, conducted in a random sample of a third of the Italian hospitals, showed that only $68 \%$ of hospitals in the country (and $37.5 \%$ in southern Italy) were able to perform at least one diagnostic test for LD [27]. In addition, more than $50 \%$ of the hospitals were able to diagnose LD by urinary antigen and/or serology test, while only $29 \%$ of the hospitals were able to perform Legionella spp. isolation.

These findings were consistent with surveillance data which showed that more than $80 \%$ of cases were diagnosed in only five regions located in the north and centre of Italy and that some southern regions had not notified a single case. At the same time, it should be noted that geographical variation in LD incidence rate could partly be related to the climate and meteorological conditions, as recently suggested for other acute respiratory infections [28].

The great majority of the European outbreaks described are related to cooling towers [29-31], and also in Italy, the few community outbreaks that occurred were due to this exposure. For this reason, many European countries are implementing new regulations for cooling towers, including their compulsory registration at local and regional level. These control measures are showing encouraging results [23]. In Italy, no registration is required for cooling towers; consequently an easy and rapid investigation is not always possible.

With regard to diagnostic methods, more than $90 \%$ of cases were diagnosed by urinary antigen detection only. It is important to underline that the use of urinary antigen test alone for LD diagnosis can lead to an underestimation of the burden of the disease, because pneumonias caused by Legionella species or serogroups different from Lp1 are not always detected by this method. Therefore, while recognising the usefulness of the urinary antigen test, it is necessary that isolation is also attempted in all patients. In 2010, according to data provided by ECDC, 652 cases in Europe (10.3\% of the total) were culture-confirmed; however, this proportion varied from o (in several countries) to $39.8 \%$ (Denmark), and Italy is in the lower part of this range [24]. Culture should, therefore, be attempted and promoted, since it is a precondition for matching clinical and environmental isolates during cluster or outbreak investigations carried out to find the source of infection. 
Furthermore, bacterial culture of clinical specimens should be promoted since the lack of clinical samples makes the identification of the source of infection impossible in those accommodation sites where positive environmental samples have been obtained. An environmental sample positive for Legionella spp. is not sufficient to determine the source of infection, although the likelihood of a certain accommodation site being the source increases when clusters of two or more cases associated with the same accommodation are reported.

To reduce underestimation of the disease and to better control Legionella spp. environmental diffusion, epidemiological surveillance must be further strengthened in Italy, diagnostic tests should be made available in all hospitals, especially in low reporting areas, and culture should be performed whenever possible.

\section{Acknowledgements}

We would like to thank all health professionals from regions, local health departments and hospitals for submitting surveillance forms.

\section{Conflict of interest}

None declared.
References

1. Borella P, Montagna MT, Stampi S, Stancanelli G, RomanoSpica V, Triassi M, et al. Legionella contamination in hot water of Italian hotels. Appl Environ Microbiol. 2005;71(10):580513. http://dx.doi.org/10.1128/AEM.71.10.5805-5813.2005. PMid:16204491. PMCid:1265926.

2. Borella P, Montagna MT, Romano-Spica V, Stampi S, Stancanelli G, Triassi M, et al. Legionella infection risk from domestic hot water. Emerg Infect Dis. 2004;10(3):457-64. http://dx.doi.org/10.3201/eid1003.020707. PMid:15109413. PMCid:3322798.

3. Euzéby JP. List of Prokaryotic names with Standing in Nomenclature - Genus Legionella. [Accessed 15 May 2012]. Available from: http://www.bacterio.cict.fr/l/legionella.html

4. Yu VL, Plouffe JF, Pastoris MC, Stout JE, Schousboe M, Widmer $A$, et al. Distribution of Legionella species and serogroups isolated by culture in patients with sporadic communityacquired legionellosis: an international collaborative survey. J Infect Dis. 2002;186(1):127-8. http://dx.doi. org/10.1086/341087. PMid:12089674.

5. Helbig JH, Bernander S, Castellani Pastoris M, Etienne J, Gaia V, Lauwers S, et al. Pan-European study on culture-proven Legionnaires' disease: distribution of Legionella pneumophila serogroups and monoclonal subgroups. Eur J Clin Microbiol Infect Dis. 2002;21(10):710-6. http://dx.doi.org/10.1007/ S10096-002-0820-3. PMid:12415469.

6. McNally C, Hackman B, Fields BS, Plouffe JF. Potential importance of Legionella species as etiologies in community acquired pneumonia (CAP). Diagn Microbiol Infect Dis. 2000;38(2):79-82. http://dx.doi.org/10.1016/ S0732-8893(00)00181-4.

7. Medarov BI, Siddiqui AK, Mughal T, Moshiyakhov M, Rossoff LJ. Legionella micdadei infection presenting as severe secretory diarrhea and a solitary pulmonary mass. Clin Infect Dis. 2004;38(7):e63-5. http://dx.doi.org/10.1086/382679. PMid:15034849.

8. Roig J, Sabria M, Pedro-Botet ML. Legionella spp.: community acquired and nosocomial infections. Curr Opin Infect Dis. 2003;16(2):145-51. http://dx.doi.org/10.1097/00001432200304000-00011. PMid:12734447.

9. Napoli C, Fasano F, latta R, Barbuti G, Cuna T, Montagna MT. Legionella spp. and legionellosis in southeastern Italy: disease epidemiology and environmental surveillance in community and health care facilities. BMC Public Health. 2010;10:660. http://dx.doi.org/10.1186/1471-2458-10-66o. PMid:21044294. PMCid:2988737.

10. Lin YE, Stout JE, Yu VL. Prevention of hospital-acquired legionellosis. Curr Opin Infect Dis. 2011;24(4):350-6. http:// dx.doi.org/10.1097/QC0.ob013e3283486c6e. PMid:21666459.

11. Montagna MT, Napoli C, Tatò D, Spilotros G, Barbuti G, Barbuti S. Clinical-environmental surveillance of legionellosis: an experience in Southern Italy. Eur J Epidemiol. 2006; 21(4):325-31. http://dx.doi.org/10.1007/s10654-006-0009-7. PMid:16685585.

12. Tablan OC, Anderson LJ, Besser R, Bridges C, Hajjeh R, Healthcare Infection Control Practices Advisory Committee. Guidelines for preventing health-care--associated pneumonia, 2003: recommendations of CDC and the Healthcare Infection Control Practices Advisory Committee. MMWR Recomm Rep. 2004;53(RR-3):1-36. PMid:15048056.

13. European Surveillance Scheme for Travel Associated Legionnaires' Disease, European Working Group for Legionella Infections (EWGLI). European Guidelines for Control and Prevention of Travel Associated Legionnaires' Disease. Jan 2005. Available from: http://www.hpa.org.uk/webc/ HPAwebFile/HPAweb_C/1274093149925

14. Linee guida italiane per la prevenzione e il controllo della legionellosi. [Italian guidelines for prevention and control of legionellosis]. Gazzetta Ufficiale della Repubblica Italiana n103 5 May 2000. Italian. Available from: http://www.simi.iss.it/ files/legiooo.pdf

15. Napoli C, latta R, Fasano F, Marsico T, Montagna MT. Variable bacterial load of Legionella spp. in a hospital water system. Sci Total Environ. 2009;408(2):242-4. http://dx.doi.org/10.1016/j. scitotenv.2009.09.039. PMid:19836825.

16. European Centre for Disease Prevention and Control (ECDC). European Legionnaires' Disease Surveillance Network (ELDSNet). Stockholm: ECDC. 2012. [Accessed 15 May 2012]. Available from: http://ecdc.europa.eu/en/activities/ surveillance/ELDSNet/Pages/index.aspx

17. Rota MC, Castellani Pastoris M, Salmaso S. Rapporto annuale sulla legionellosi in Italia nel 2001 [Legionellosis in Italy: 2001 annual report]. Not Ist Super Sanità. 2002;15(10):1115. Italian. Available from: http://www.iss.it/binary/publ/ publi/0210.1107342628.pdf 
18. Rota MC, Caporali MG, Napoli C, Bella A, Giannitelli S, Scaturro $M$, et al. Rapporto annuale sulla legionellosi in Italia nel 2010 [Legionellosis in Italy: 2010 annual report]. Not Ist Super Sanità. 2011;24(10):3-9. Italian. Available from: http://www. iss.it/binary/publ/cont/onlineottobre.pdf

19. Ricketts KD, Yadav R, Rota MC, Joseph CA, on behalf of the European Working Group for Legionella Infections. Characteristics of reoffending accommodation sites in Europe with clusters of Legionnaires' disease, 2003-2007. Euro Surveill. 2010;15(40):pii=19680. Available from: http://www. eurosurveillance.org/ViewArticle.aspx?Articleld=19680

20. Istituto Nazionale di Statistica (Istat). Istat National demographic statistics. [Accessed 30 Oct 2012]. Available from: http://demo.istat.it/index_e.html

21. Rota MC, Scaturro M, Fontana S, Foroni M, Boschetto G, Trentin L, Blengio G, Bandettini G, Buratto T, Caporali MG, Napoli C, Ricci ML. Cluster of travel-associated Legionnaires' disease in Lazise, Italy, July to August 2011 . Euro Surveill. 2011;16(40):pii=19982. Available from: http://www. eurosurveillance.org/ViewArticle.aspx?Articleld=19982

22. Rota MC, Pontrelli G, Scaturro M, Bella A, Bellomo AR, Trinito $\mathrm{MO}$, et al. Legionnaires' disease outbreak in Rome, Italy. Epidemiol Infect. 2005;133(5):853-9. http://dx.doi.org/10.1017/ So950268805004115. PMid:16181505. PMCid:2870316.

23. Joseph CA, Ricketts KD, on behalf of the European Working Group for Legionella Infections. Legionnaires' disease in Europe 2007-2008. Euro Surveill. 2010;15(8):pii=19493. Available from: http://www.eurosurveillance.org/ViewArticle. aspx?Articleld $=19493$

24. Campese C, Bitar D, Jarraud S, Maine C, Forey F, Etienne J, et al. Progress in the surveillance and control of Legionella infection in France, 1998-2008. Int J Infect Dis. 2011;15(1):e30-7. http:// dx.doi.org/10.1016/j.ijid.2010.09.007. PMid:21109475.

25. European Centre for Disease Prevention and Control (ECDC). Legionnaires' disease in Europe, 2010. Stockholm: ECDC. Jul 2012. Available from: http://ecdc.europa.eu/en/publications/ Publications/SUR-Legionnaires-disease-surveillance-2010.pdf

26. Rota MC, Cawthorne A, Bella A, Caporali MG, Filia A, D’Ancona $F$, et al. Capture-recapture estimation of underreporting of legionellosis cases to the National Legionellosis Register: Italy 2002. Epidemiol Infect. 2007;135(6):1030-6. http:// dx.doi.org/10.1017/So950268806007667. PMid:17176499. PMCid:2870651.

27. Rota MC, D'Ancona F, Cavallaro GM, Bagnato B, Nacca G, Serra R. Availability of laboratory tools for microbiological diagnosis of lower respiratory tract infections in Italian hospitals. Ann Ig. 2007;19(6):509-17. Italian. PMid:18376571.

28. du Prel JB, Puppe W, Gröndahl B, Knuf M, Weigl JA, Schaaff F, et al. Are meteorological parameters associated with acute respiratory tract infections? Clin Infect Dis. 2009;49(6):861-8. http://dx.doi.org/10.1086/605435. PMid:19663691.

29. Nguyen TM, Ilef D, Jarraud S, Rouil L, Campese C, Che D, et al. A community-wide outbreak of legionnaires disease linked to industrial cooling towers-how far can contaminated aerosols spread? J Infect Dis. 2006;193(1):102-11. http://dx.doi. org/10.1086/498575. PMid:16323138.

30. Barricarte A, García Cenoz M, Castilla J, Aldaz P. Current legionellosis outbreak with 139 cases in Pamplona, Spain. Euro Surveill. 2006;11(23):pii=2967. Available from: http:// www.eurosurveillance.org/ViewArticle.aspx?Articleld=2967. PMid:16819117.

31. García-Fulgueiras A, Navarro C, Fenoll D, García J, GonzálezDiego P, Jiménez-Bu-uales T, et al. Legionnaires' disease outbreak in Murcia, Spain. Emerg Infect Dis. 2003;9(8):915-21. http://dx.doi.org/10.3201/eido908.030337. PMid:12967487. PMCid:3020623. 